\title{
Flushing ports of totally implantable venous access devices, and impact of the Huber point needle bevel orientation: experimental tests and numerical computation
}

\author{
This article was published in the following Dove Press journal: \\ Medical Devices: Evidence and Research \\ 12 April 2012 \\ Number of times this article has been viewed
}

\author{
Gérard Guiffant ${ }^{1}$ \\ Jean Jacques Durussel' \\ Patrice Flaud' \\ Jean Pierre Vigier ${ }^{\prime}$ \\ Jacques Merckx ${ }^{1,2}$ \\ 'Université Paris Diderot, Paris, \\ France; ${ }^{2}$ University Teaching Hospital \\ Necker-Enfants Malades, Paris, France
}

\begin{abstract}
The use of totally implantable venous access devices developed as a medical device allowing mid- and long-term, frequent, repeated, or continuous injection of therapeutic products, by vascular, cavitary, or perineural access. The effective flushing of these devices is a central element to assure long-lasting use. Our experimental work demonstrates that directing the Huber point needle opening in the diametrically opposite direction of the implantable port exit channel increases the flushing efficiency. These results are consolidated by numerical computations, which support recommendations not only for their maintenance, but also for their use.
\end{abstract}

Keywords: implantable ports, totally implantable venous access devices (TIVADs), flushing, obstruction, prevention

\section{Introduction}

Totally implantable venous access devices (TIVADs) have been in use for more than two decades. They allow repeated vascular (venous, arterial), body cavity (pleural, peritoneal, and intradural), and perineural accesses for drug administration (anticancer, antibiotics, analgesics, parenteral nutrition, blood transfusion) as well as blood collection.

These devices have proved to be safe and effective in overcoming problems of repeated venous access when patients need regular intravenous therapy. Not only do they respect the venous capital, but they also bring comfort, autonomy, and safety to the patients, and ease and reliability of use for the health care workers. Their characteristics, risks, and benefits are well described. ${ }^{1-7}$ Their setting, use, and maintenance are detailed in various protocols and in at least one national recommendation. ${ }^{8-12}$ If these documents mention that an appropriate flushing is an absolute necessity, none have described the technique to be used.

Previous works on central and peripheral intravenous access devices ${ }^{13,14}$ showed that flushing efficacy was technique-dependent (pulsed flushing versus continuous flushing) and, therefore, flushing efficacy could be optimized with a potential increase of the lifespan of devices and a decrease of obstructive and infectious risks.

The flushing efficacy of a cavity, catheter, or an implantable port depends on two groups of factors: on one hand, the physicochemical process of molecule adhesion and deadhesion and, on the other hand, a hydrodynamic process linked to the shear stress forces of the flush on the internal surface. In the case of implantable ports, this force is based on the intensity of the flow and on the orientation of the Huber point needle (HPN) bevel.
Correspondence: Gérard Guiffant Université Paris Diderot, MSC, UMR CNRS 7057, 10 rue Alice Domon et Léonie Duquet, 75205 Paris, cedex 13, France Fax +330157276211

Email gerard.guiffant@univ-paris-diderot.fr 
The objective of this experimental work was to quantify the effect of the HPN bevel orientation with respect to the exit channel on the flushing efficacy of an implantable port without catheter. The experimental results were completed by a numerical computation describing the dynamics of the outflow.

\section{Material and methods}

The port geometry is shown in Figure 1. The reservoir is cylindrical and there is an exit channel at the port base which connects to the central venous catheter. Its top is made of a compressed silicone membrane (septum) which can be punctured by a specific needle (HPN).

The port characteristics (Polysite ${ }^{\circledR}$, séries 2000, 3000, and 4000; Pérouse Médical, Ivry le Temple, France) are summarized in Table 1.

Each port was filled with an aqueous solution of $0.1 \%$ dodecyl sulfate sodium (DSS) by a syringe and an HPN inserted in the septum center (point B). After an incubation of 48 hours at $37^{\circ} \mathrm{C}$, the ports were emptied and flushed with $30 \mathrm{~mL}$ of pure water with a sloped outflow channel, to completely washout the DSS.

Once cleansed, each port was filled with an aqueous solution of fibronectin $(5 \mu \mathrm{g} / \mathrm{mL})$ and kept for 2 hours at $37^{\circ} \mathrm{C}$. The nonadherent fibronectin was eliminated by a slow injection of air through the HPN. A saline solution of bovine serum albumin $(10 \mathrm{mg} / \mathrm{mL})$ was then injected and the ports incubated 24 hours at $37^{\circ} \mathrm{C}$. Again, each port was flushed by a slow injection of air through the HPN to eliminate the nonadherent albumin. The recovered amount was titrated. Fibronectin and albumin were selected because both are physiological blood proteins. Furthermore, fibronectin easily

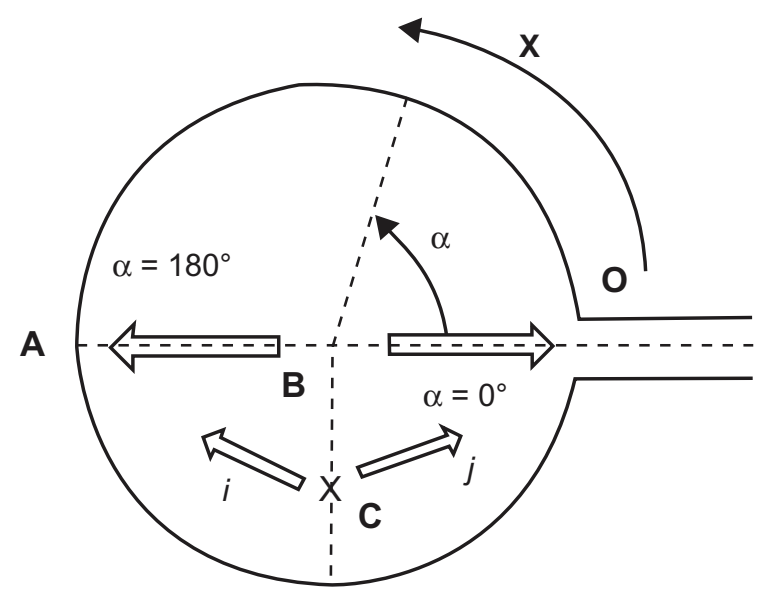

Figure I Bidimensional schematic representation of a port: (A) The diametrically opposite point of the exit channel (bottom); (B) Septum center; $(\alpha)$ the angle between the needle bevel opening and the exit channel; (i) and (j) indicate the directions of the needle bevel opening when the needle insertion point is $C$; $(x)$ the curvilinear coordinate from $\mathrm{O}$ to $\mathrm{A}$.
Table I Port characteristics

\begin{tabular}{llll}
\hline Type: $^{\text {Polysite }}{ }^{\circledR}$; Perouse Médical & $\mathbf{2 0 0 0}$ & $\mathbf{3 0 0 0}$ & $\mathbf{4 0 0 0}$ \\
\hline Port diameter $(\mathrm{mm})$ & 8 & $\mathrm{II}$ & 13 \\
Port internal volume $(\mathrm{mL})$ & 0.15 & 0.3 & 0.4 \\
Septum diameter $(\mathrm{mm})$ & 7.5 & 10.5 & 12.1 \\
\hline
\end{tabular}

and strongly adheres to biomaterials and blood products, and also promotes the adhesion of albumin and other proteins. ${ }^{15-19}$ The ports were flushed with $10 \mathrm{~mL}$ of $\mathrm{NaCl} 0.9 \%$ by an autopulsed syringe (55-1144; Harvard Apparatus, Les Ulis, France) locked to the $19 \mathrm{G}$ and $22 \mathrm{G} \mathrm{HPN} .{ }^{8}$ Two series of tests were performed with the HPN inserted in the septum center (point "B" in Figure 1), one series with the bevel opening directed toward the exit channel $\left(\alpha=0^{\circ}\right)$, and another with the bevel opening toward the bottom of the port $\left(\alpha=180^{\circ}\right)$.

As good clinical practices recommend changing the needle insertion point, a site (point " $\mathrm{C}$ " in Figure 1) located at half the radius length of the port side, on an axis perpendicular to the central site (A-O) was selected. Two other series of tests were performed with the HPN inserted there, one with the bevel opening directed toward the exit channel $(j)$, and another with the bevel opening toward the bottom of the port $(i)$. The flush solution was collected to obtain the proteins extracted by the flushing.

At insertion point $\mathrm{B}$, six tests were performed for each of the 36 combinations: three port sizes, two HPN gauges (19G and 22G), two orientations of the bevel $\left(\alpha=0^{\circ}\right.$ and $\left.\alpha=180^{\circ}\right)$, and three flow rates $\left(0.25-0.5^{-1} \mathrm{~mL} / \mathrm{second}\right)$.

At insertion point $\mathrm{C}$, six tests were performed with one port size (13 mm diameter), a 22G HPN, two orientations of the bevel ( $i$ directed to $\mathrm{A}$ and $j$ directed to $\mathrm{O}$; see Figure 1), and three flow rates $\left(0.25-0.5^{-1} \mathrm{~mL} / \mathrm{second}\right)$.

Albumin was titrated using an ultraviolet spectrophotometer at $280 \mathrm{~nm}$ (Gilson $112 \mathrm{UV} / \mathrm{VIS}$ detector; Gilson, Middleton, WI). Results are reported in percent of extracted albumin and are calculated by the amount recovered after flushing with $\mathrm{NaCl}$ divided by the amount filled minus the amount recovered after flushing with air.

\section{Statistical analysis}

The Mann-Whitney $U$ test was used on means. Statistical significance thresholds are shown in Figures 2-5 using the classical correspondence: ${ }^{*} 0.01<P<0.05$; ${ }^{* *} 0.001<$ $P<0.01 ;{ }^{* * *} P<0$.

\section{Experimental results}

The results from insertion point B are summarized in Figures 2 and 3. Each column represents the mean 
A

Port diameter: $8 \mathrm{~mm}$, Huber needle: 19G,

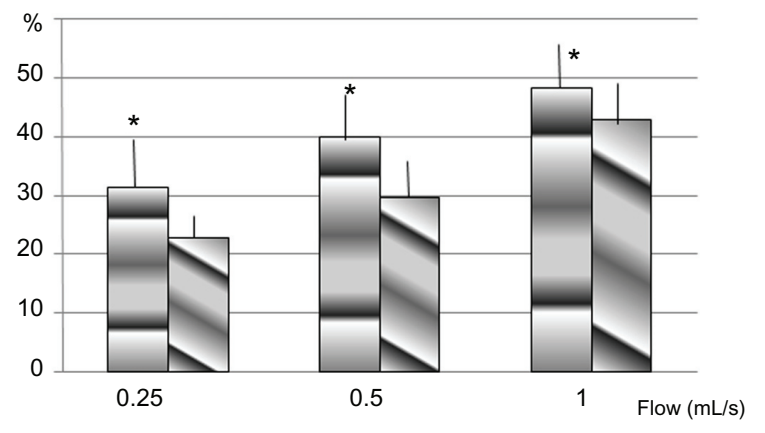

Port diameter: $11 \mathrm{~mm}$, Huber needle: 19G,

B
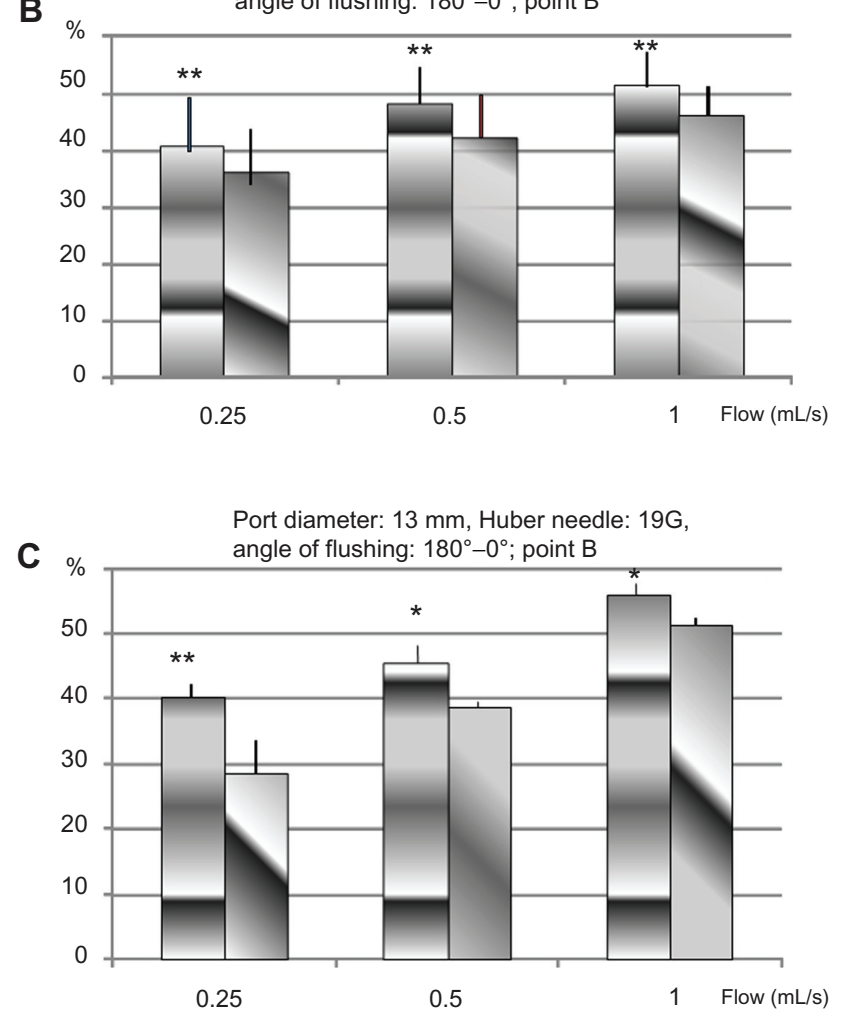

Figure 2 Percentage of of proteins removed in TIVADs of diameters $8 \mathrm{~mm}(\mathbf{A})$, II mm (B), and $13 \mathrm{~mm}(\mathbf{C})$, with a Huber point needle of I9G, for two orientations of the flow, from the point B: $0^{\circ}$ towards the exit channel, and $180^{\circ}$ towards the bottom of the cavity.

Abbreviations: $G$, gauge; TIVAD, totally implantable venous access device.

percentage of extracted proteins according to the flushing flow for each type of implantable port size, the needle gauge, and the bevel-opening orientation. The mean percentage of extracted proteins ranged between $21 \%$ and $55 \%$. The lowest amount was recovered with a $22 \mathrm{G} \mathrm{HPN}$, including the slowest flow rate $(0.25 \mathrm{~mL} / \mathrm{second})$ with the bevel opening directed toward the outflow channel $\left(\alpha=0^{\circ}\right)$. The port size did not influence the amount received. The highest amount was recovered with a $19 \mathrm{G} \mathrm{HPN}$, including the fastest flow rate $(1 \mathrm{~mL} / \mathrm{second})$ with the bevel opening toward
A

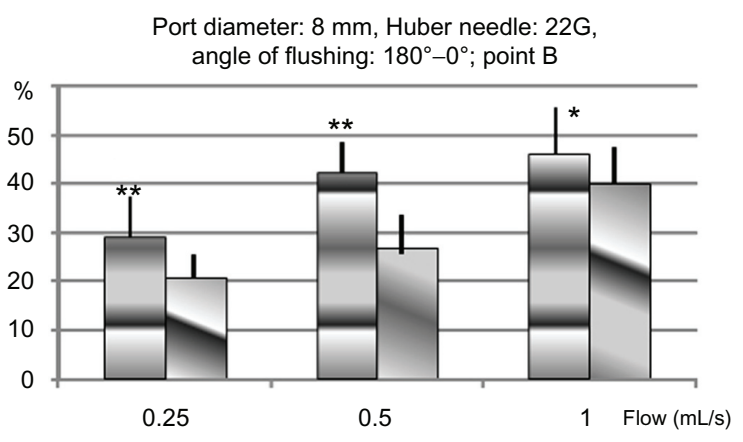

Port diameter: $11 \mathrm{~mm}$, Huber needle: 22G,

B

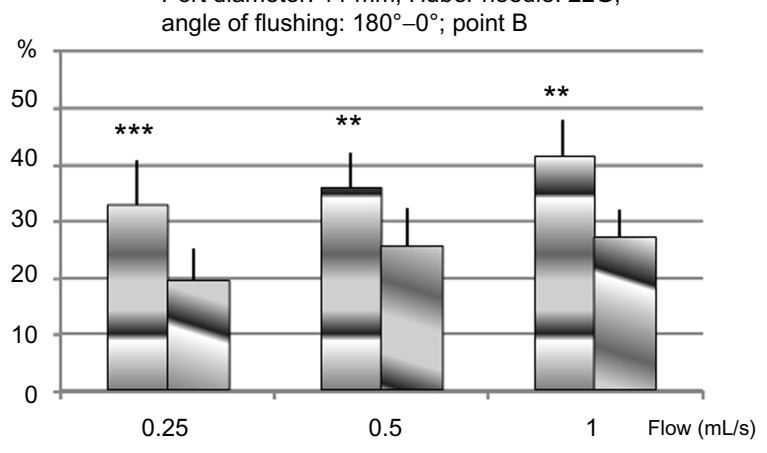

Port diameter: $13 \mathrm{~mm}$, Huber needle: $22 \mathrm{G}$, angle of flushing: $180^{\circ}-0^{\circ}$; point $\mathrm{B}$

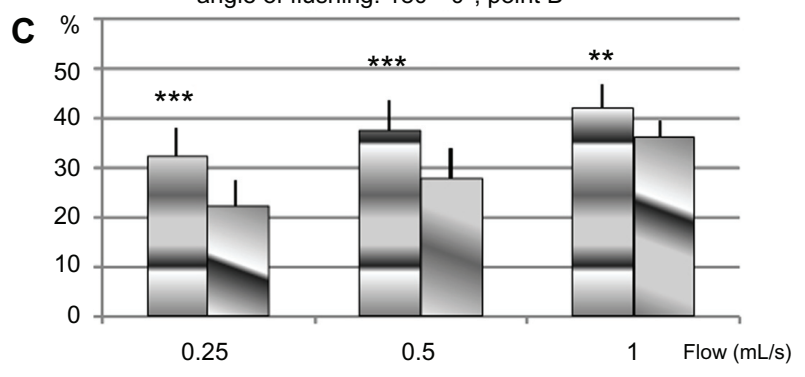

Figure 3 Percentage of proteins removed in TIVADs of diameters $8 \mathrm{~mm}(\mathbf{A})$, II mm (B), and $13 \mathrm{~mm}($ C), with a Huber point needle of 22G, for two orientations of the flow, from the point $\mathrm{B}: 0^{\circ}$ towards the exit channel, and $180^{\circ}$ towards the bottom of the cavity.

Abbreviations: G, gauge; TIVAD, totally implantable venous access device.

the bottom of the port $\left(\alpha=180^{\circ}\right)$ at the largest port size (13 mm diameter) (see Figure 2B). The flushing efficacy increased with the flow rate, whatever the mix of needle gauge, port diameter, or orientation of the needle bevel opening. Furthermore, the efficiency increased in every configuration of flow rate, needle gauge, and port diameter when the needle bevel opening was directed toward the bottom of the port $\left(\alpha=180^{\circ}\right)$.

The results of insertion point $C$ expressed in average percentage of extracted proteins are shown in Figures 4 and 5. These results are in agreement with the results from insertion point B: the highest efficiency is obtained when the needle 
Port diameter: $13 \mathrm{~mm}$, Huber needle 22G, direction of flushing: $i, j$, point $C$

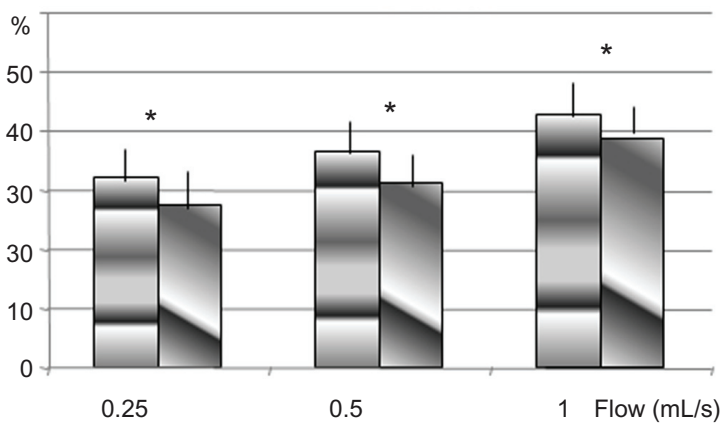

Figure 4 Percentage of proteins removed in TIVAD of $13 \mathrm{~mm}(\mathbf{c})$, with an HPN of $22 \mathrm{G}$, for two orientations of the flow from the point C: $i$ towards the bottom of the cavity, $j$ towards the exit channel.

Abbreviations: G, gauge; HPN, Huber point needle; TIVAD, totally implantable venous access devices.

bevel opening is directed toward the bottom of the port $(i)$ as shown in Table 2.

Cross comparisons show that the needle insertion point has no or little effect on flushing efficiency (see Figure 5A and B; Tables 3 and 4).

\section{Numerical computation}

The experimental results are consolidated by numerical computations that show the flow structure (laminar flow) in a cavity filled with a liquid (as ports in use are). The cavity bidimensional geometry is shown in Figure 1. The circular cavity has a diameter of $8 \mathrm{~mm}$. The dynamic viscosity of the flush solution (normal saline) used is $\eta=10^{-3} \mathrm{~Pa}-\mathrm{s}$, and its volume mass was $\rho=10^{3} \mathrm{kgm}^{-3}$. The needle was inserted in the port center (point B). The angle of injection $\alpha=0^{\circ}$ corresponds to the axis between the point $\mathrm{B}$ and the exit channel $\mathrm{O}$.

Figure 6 shows the lines of a continuous flow for four injection angles $\alpha=0^{\circ}, 45^{\circ}, 135^{\circ}$, and $180^{\circ}$. For $\alpha=180^{\circ}$, the lines fold up on the cavity bottom and follow the outline of the reservoir wall. The flow is drawn toward the exit channel. On the other hand, when $\alpha=0^{\circ}$, the flow divides. One part recirculates, in the rheological sense, and remains inside the cavity. One can quantify the flushing efficiency by calculating the shear stress force at each point along the cavity inside wall. The value, quoted as $\Phi$, is proportional to the friction force by surface unit of the cavity and therefore, represents the local density of flow of proteins extracted by friction. Figure 7 shows that $\Phi$ is always higher when $\alpha=180^{\circ}$ than when $\alpha=0^{\circ}$. This is obviously in agreement with the tests results. One also notices that $\Phi$ is always close to 0 in an area more or less important around point $\mathrm{A}$ at the
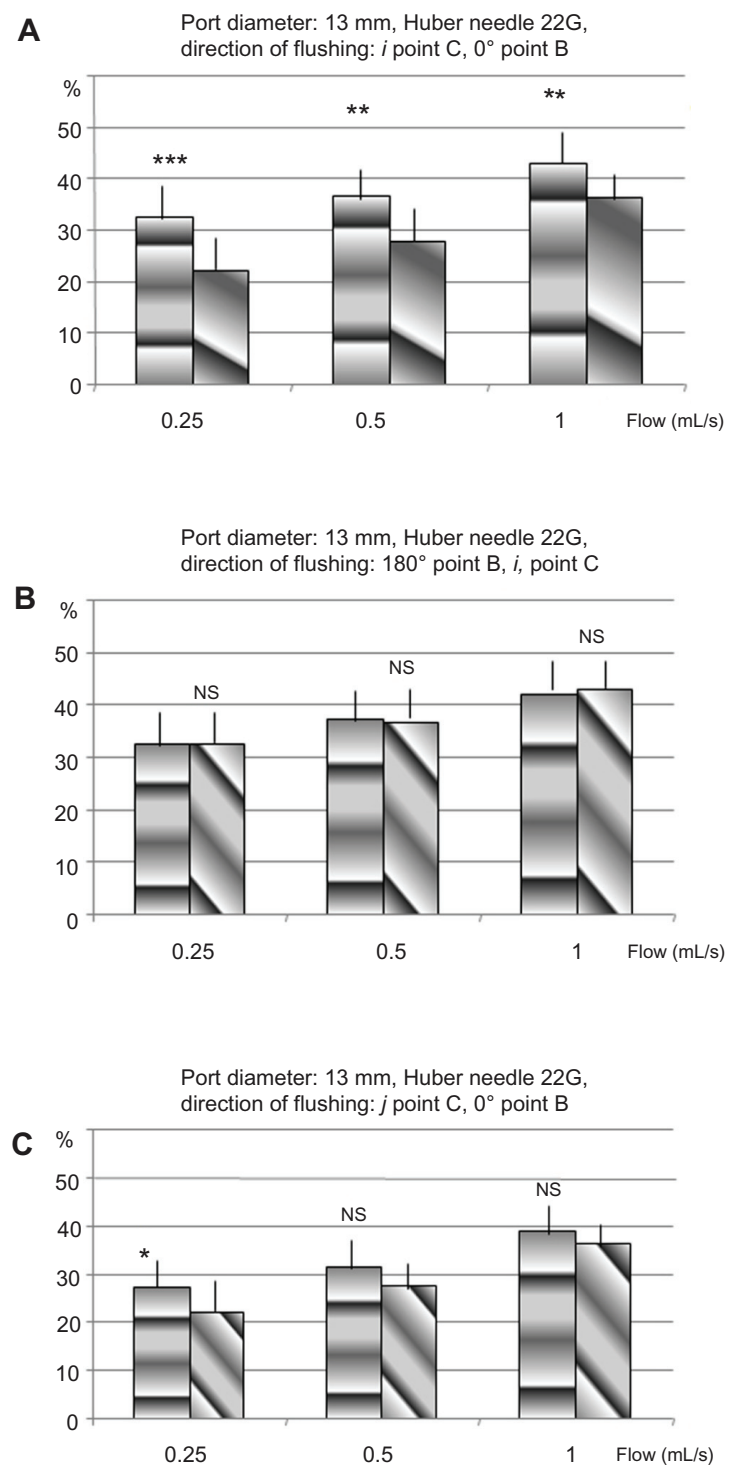

Figure 5 Crossed comparison of the percentage of removed proteins for different orientations of the flow from the points $B$ and $C$ in TIVAD of $13 \mathrm{~mm}$, with a HPN of $22 \mathrm{G}$.

Abbreviations: G, gauge; HPN, Huber point needle; NS, nonsignificant; TIVAD, totally implantable venous access devices.

bottom of the cavity. This is due to a stop point of the flow for both $\alpha=180^{\circ}$ and $\alpha=0^{\circ}$.

The global efficiency of the flushing can be estimated by integrating $\Phi$. The computation leads then to a value, quoted as $\Omega$, which is proportional to the mass flow collected by flushing.

Table 2 Percentage of extracted proteins

\begin{tabular}{llll}
\hline Flow rate & $\boldsymbol{i}$ & $\boldsymbol{j}$ & $\boldsymbol{P}$ value \\
\hline $0.25 \mathrm{~mL} /$ second & $32.4 \%$ & $27.4 \%$ & $0.01<\mathrm{P}<0.05$ \\
$0.50 \mathrm{~mL} /$ second & $36.7 \%$ & $31.3 \%$ & $0.01<\mathrm{P}<0.05$ \\
$\mathrm{I} \mathrm{mL} /$ second & $42.9 \%$ & $38.9 \%$ & $0.01<\mathrm{P}<0.05$ \\
\hline
\end{tabular}

Note: Bevel opening toward the outflow channel versus bottom of the port with an off-centered needle insertion point. 
Table 3 Percentage of extracted proteins

\begin{tabular}{llll}
\hline Flow rate & $\boldsymbol{j}$ & $\boldsymbol{\alpha}=\mathbf{0}^{\circ}$ & $\boldsymbol{P}$ value \\
\hline $0.25 \mathrm{~mL} /$ second & $27.1 \%$ & $22.1 \%$ & Nonsignificant \\
$0.50 \mathrm{~mL} /$ second & $31.3 \%$ & $27.7 \%$ & Nonsignificant \\
$\mathrm{I} \mathrm{mL} / \mathrm{second}$ & $38.9 \%$ & $36.2 \%$ & Nonsignificant \\
\hline
\end{tabular}

Note: Bevel opening toward the outflow channel with a centered versus off-centered needle insertion point.

Results are reported in Figure 8 which shows the $\Omega$ variations according to time from the initial moment before beginning to flush the cavity and according to the flushing technique used, needle bevel-opening orientation, and with or without a movement of oscillation around its vertical axis.

The results without oscillations are presented on Figure 8 for four bevel needle-opening orientations $\left(\alpha=0^{\circ}\right.$, $45^{\circ}, 135^{\circ}$, and $\left.180^{\circ}\right)$. The numerical computation reproduces the experimental test data. The most efficient flushing is obtained when $\alpha=180^{\circ}$ and the less efficient when $\alpha=0^{\circ}$. Keeping in mind that an unflushed area remains in the neighborhood of the point A, a movement of oscillation of the needle around its axis could be performed (as recommended by numerous clinicians). The results of that technique, with an oscillation of $\pm 90^{\circ}$ for both $\alpha=0^{\circ}$ and $180^{\circ}$ are shown in Figure 8. As expected, the efficiency lies between that of $\alpha=180^{\circ}$ and $\alpha=0^{\circ}$ without needle oscillations. A compromise could be to impose a movement of oscillation of very small amplitude $\approx \pm 10^{\circ}$ around $\alpha=180^{\circ}$. The result is show as the dotted line in Figure 8 . We obtained a global efficiency close to (but always below) the maximum while avoiding the absence of flushing in the neighborhood of point A.

\section{Discussion}

The purpose of this work was to test, under controlled conditions, the effect of the needle bevel orientation on the efficiency of flushing implantable ports with a continuous infusion of normal saline. Maintaining the vacuity of vascular access, specifically venous access, is of upmost importance for the medical, psychological, and financial costs. To avoid obstruction is the first and foremost reasonable use to limit deposits in TIVADs by conducting effective flushing.

Table 4 Percentage of extracted proteins.

\begin{tabular}{llll}
\hline Flow rate & $\alpha=180^{\circ}$ & $\boldsymbol{i}$ & $\boldsymbol{P}$ value \\
\hline $0.25 \mathrm{~mL} /$ second & $32.4 \%$ & $32.4 \%$ & Nonsignificant \\
$0.50 \mathrm{~mL} /$ second & $37.4 \%$ & $36.7 \%$ & Nonsignificant \\
I mL/second & $42 \%$ & $42.9 \%$ & Nonsignificant \\
\hline
\end{tabular}

Note: Bevel opening toward the port bottom $\left(\alpha=180^{\circ}\right)$ with a centered versus off-centered needle insertion point.
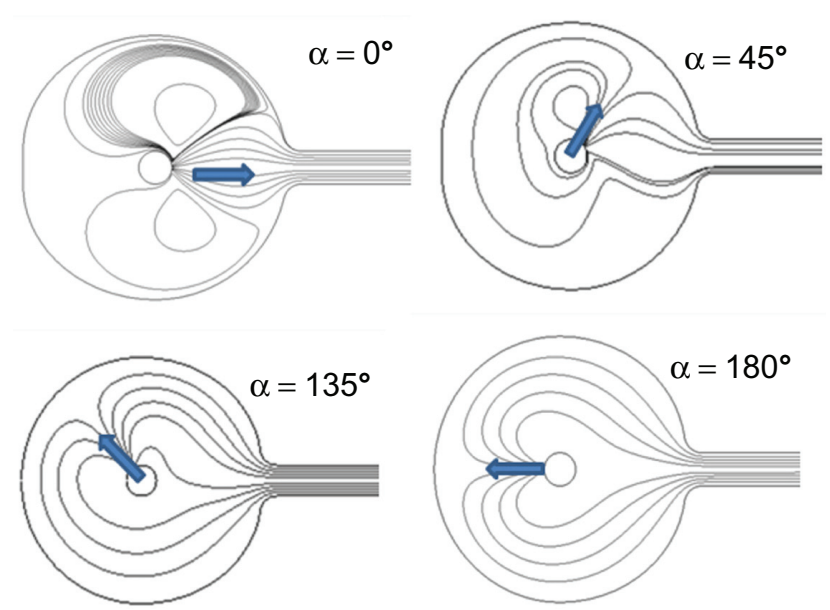

Figure 6 Lines of flow in a circular cavity for four injection angles.

Flushing with the correct solution and technique is then fundamental to maintain patency of the catheter. The use of heparinized solution $(10 \mathrm{U} / \mathrm{mL})$ to ensure catheter patency is controversial and efficacy is not proven. Flushing with Heparin solution is no more beneficial than flushing with $\mathrm{NaCl} 0.9 \%$ alone. ${ }^{9,11}$ Because an intraluminal fibrin sheet or blood clot might serve as a nidus for microbial colonization after the perfusion of intravascular catheters by medication or parenteral nutrition, it is very important to realize effective flushing and to withdraw any biological or chemical component.

We specified the effective pulsed flushing technique, ${ }^{13}$ but no publication specifies the influence of the direction of the opening of HPN in the port. The experimental results of the study pollution from flushing of ports, consolidated by the results of numerical computation, show that the shear stress forces are always more important when the injected flow is directed towards the bottom of the port, even if the HPN is not inserted in the center of the

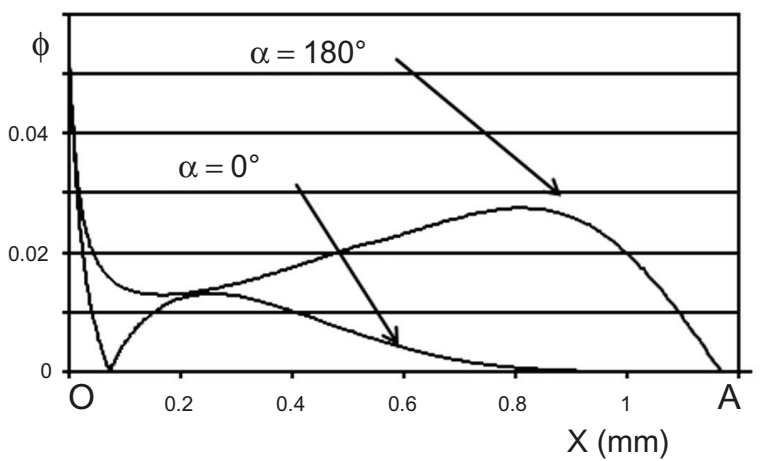

Figure $7 \Phi$ numerical values along the wall of the cavity according to the curvilinear abscissa $(X)$ between points $O$ and $A$ for the two directions of the flow $\alpha=180^{\circ}$ and $\alpha=0^{\circ}$. 


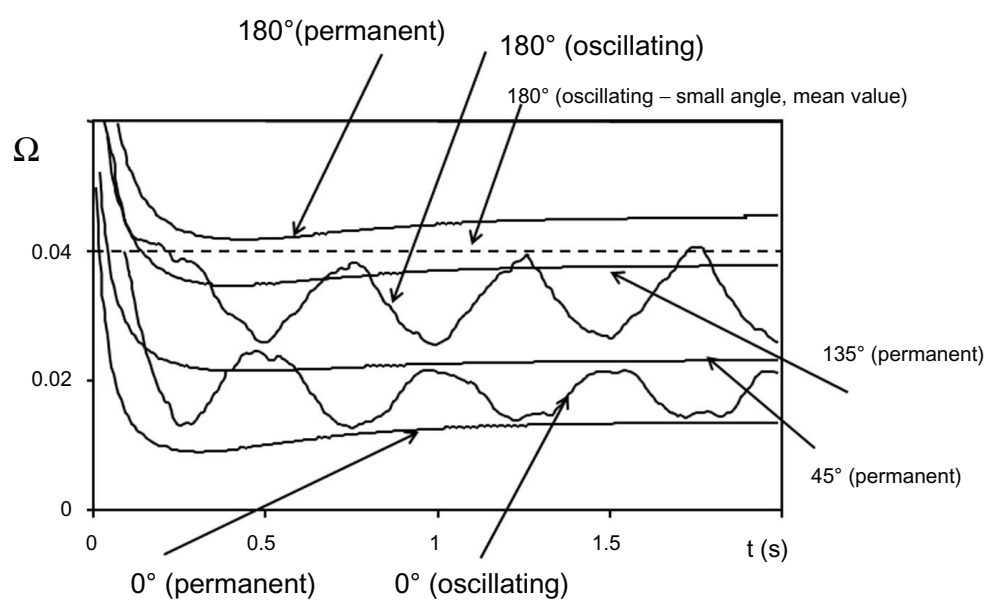

Figure 8 Distribution of numerical values as a function of time for different situations of flushing in permanent or impermanent conditions.

septum port. When the flow is directed towards the bottom of the port (point $\mathrm{A}, \alpha=180^{\circ}$ ), the flushing flow redistributes on the totality of the walls of the port and the intensity of the shear stress force of cutting is major. If the flow is directed towards the exit channel, only a small part of the flow is redirected towards the walls of the port. The intensity of the shear stress force is strongly decreased and the recirculating flow favors the parietal deposit of all or any of the perfusate (proteins, lipids, contrast medium) or of figurative elements of the blood. This experimental work expresses and confirms fundamental basic principles to establish a protocol of TIVAD use: flushing, perfusing, and blood collection. These principles are physically valid whatever the position of the insertion point of the HPN in the septum. Optimal flushing is obtained with a small-gauge HPN with its bevel opening opposite to the exit channel. This corresponds to the recommendations of use of this type of needle. It may be interesting, during the flushing, to perform an oscillating movement of very low amplitude (for example at point $\mathrm{B}$, $\alpha=180^{\circ} \pm \approx 10^{\circ}$ ) to try to eliminate the deposits in the stop point $A$ at the bottom of the port (see Figure 6). Oscillations of big amplitude around the needle insertion points (B or C, see Figure 1) are only of average efficiency, and much less than in the fixed injection. The rotations of HPN on its vertical axis, as recommended by some protocols, are also less effective and must not be performed. Furthermore this movement sometimes causes pain in patients. It seems desirable to direct the flow of a drip to the bottom of the port, although the flow is mostly lower than the flow of the flushing. Indeed, the hydrodynamic effect which accounts for flushing occurs in the same way during the infusion to prevent or limit the parietal deposition. If the flow is directed towards the output channel, the redistribution of the flow leads to a recirculation, which promotes the wall deposition of all or part of the perfusate, which is then trapped in the port.

\section{Conclusion}

The prevention of the occlusion of TIVADs is imperative. The definition of protocols of use of the TIVADs based on the hemodynamic principles mentioned above is a simple, effective and economic therapeutic for use by nursing teams to avoid or reduce the obstruction of the TIVADs. The knowledge of the physical principles which govern the flows in these devices allows for the reduction of mechanical manipulations, which are sources of medical complications $^{10-12}$ in particular infections. Nevertheless, no article or recommendations appear in the literature concerning the orientation of the opening of HPN used with TIVADs.

We have shown that the direction of the jet of flushing and perfusion is an important factor for the prevention of the accumulation of biological and/or chemical deposit (contrast agent for example, due to an increasing use of TIVADs) and to assure the patency of the device. We hope that this study will contribute to the definition of good practices in an area of increasing importance.

\section{Aknowledgments}

The authors thank Perouse Medical for supplying them with the TIVADs necessary for the study.

\section{Disclosure}

The authors report no conflicts of interest in this work.

\section{References}

1. Adlera A, Yanivb I, Steinbergc R, et al. Infectious complications of implantable ports and Hickman catheters in paediatric haematologyoncology patients. $J$ Hosp Infect. 2006;62(3):358-365. 
2. Ahmadi J, Izadyar M, Ashjaei B, et al. Study of advantages and disadvantages of totally implanted venous access device. Acta Med Iran. 2006;44(3):199-202.

3. Hall P, Cedermark B, Swedenborg J. Implantable catheter system for long-term intravenous chemotherapy. J Surg Oncol. 1989;41(1): $39-41$.

4. Herrmann KA, Waggershauser T, Sittek H, Reiser MF. Liver intraarterial chemotherapy: use of the femoral artery for percutaneous implantation of catheter-port systems. Radiology. 2000;215(1):294-299.

5. Hirota T, Yamagami T, Tanaka O, et al. Brain infarction after percutaneous implantation of port-catheter system via the left subclavian artery. Br J Radiol. 2002;75(898):799-804.

6. Yamagami T, Kato T, Iida S, Hirota T, Nishimura T. Management of end hole in placement of port-catheter system for continuous hepatic arterial infusion chemotherapy using the fixed catheter tip method. Am J Roentgenol. 2005;184(4):1332-1339

7. Yamagami T, Terayama K, Yoshimatsu R, Matsumoto T, Miura H, Nishimura T. Use of N-butyl cyanoacrylate in implantation of a portcatheter system for hepatic arterial infusion chemotherapy with the fixed-catheter-tip method: is it necessary? Am J Roentgenol. 2008; 191(5):1523-1529.

8. MALER G. Sécurité des dispositifs médicaux et utilisation des chambres à cathéters implantables et des aiguilles. ANAES Lettre Circulaire. DGS/EM 1. N 96-6225. 28 octobre 1996.

9. MALER G. Evaluation de la qualité de l'utilisation et de la surveillance des chambres à cathéters implantables. ANAES Lettre Circulaire. DGS/ DH N 98-249. 20 avril 1998.

10. Baskin JL, Pui CH, Reiss U, et al. Management of occlusion and thrombosis associated with long term indwelling central venous catheters. Lancet. 2009;374(9684):159-169.
11. Pittiruti M, Hamilton H, Biffi R, MacFie J, Pertkiewicz M. ESPEN Guidelines on Parenteral Nutrition: central venous catheters (access, care, diagnosis and therapy of complications). Clin Nutr. 2009;28(4): 365-377.

12. Ragni MV, Journeycake JM, Brambilla DJ. Tissue plasminogen activator to prevent central venous access device infections: a systematic review of central venous access catheter thrombosis, infection, and thromboprophylaxis. Haemophilia. 2008;14(1):30-38.

13. Guiffant G, Durussel JJ, Merckx J, Flaud P, Vigier J-P, Mousset P. Flushing of intravascular access devices (IVADs) Efficacy of pulsed and continuous infusions. J Vasc Access. July 11, 2011. [Epub ahead of print.]

14. Vigier JP, Merckx J, Coquin JY, Flaud P, Guiffant G. The use of a hydrodynamic bench for experimental simulation of flushing venous catheters: impact of the technique. ITBM-RBM Innovation et Technologie en Biologie Medicine-Revue de Tech Biomediale. 2005;26(2): 147-149.

15. Chevallier P, Haïdopoulos M, Mantovani D. Biomatériaux: implantation d'une prothèse artérielle synthétique. Le médecin du Québec. 2003;38(6):115-123.

16. Drumheller PD. Materials and methods for the immobilization of bioactive species onto polymeric substrates. United States Patent 5897955. April 27, 1999.

17. Horbett TA. The role of adsorbed proteins in animal cell adhesion. Colloids Surf B Biointerfaces. 1994;2(1-3):225-240.

18. Pellenc D, Berry H, Gallet O. Adsorption-induced fibronectin aggregation and fibrillogenesis. J Colloid Interface Sci. 2006; 298(1):132-144

19. Potts JR, Campbell ID. Fibronectin structure and assembly. Curr Opin Cell Biol. 1994;6(5):648-655.
Medical Devices: Evidence and Research

\section{Publish your work in this journal}

Medical Devices: Evidence and Research is an international, peerreviewed, open access journal that focuses on the evidence, technology, research, and expert opinion supporting the use and application of medical devices in the diagnosis, treatment and management of clinical conditions and physiological processes. The identification of novel

\section{Dovepress}

devices and optimal use of existing devices which will lead to improved clinical outcomes and more effective patient management and safety is a key feature. The manuscript management system is completely online and includes a quick and fair peer-review system. Visit http://www. dovepress.com/testimonials.php to read real quotes from authors. 